\title{
Organisation of asthma care in primary health care in Mid-Sweden
}

\section{Karin Lisspers*, Björn Ställberg, Mikael Hasselgren, Gunnar Johansson, Kurt Svärdsudd}

\author{
Department of Public Health and Caring Sciences, Section of Family Medicine and \\ Clinical Epidemiology, Science Park, SE-751 85 Uppsala, Sweden
}

Received 23 February 2005; accepted 4 March 2005

\begin{abstract}
KEYWORDS
Asthma;

Primary health care;

Quality of health care;

Asthma clinic;

Spirometer

Summary

Aim: To investigate the organisation of astiplad e in 240 primary health care centres (PHCCs) in Mid-Swedeh. Ce

Methods: A cross. se cicnal Study. Main outcpros s were occurrence and structure of numse based asthma clinics acrord no to hationally recommended criteria, and access and use of spirbireters.

Results 238 OHCS (99\%) responded. $16 \%$ reported a complete, and $37 \%$ an ir cornoplece, asthma clinic. 47\% of PHCCs had no asthma clinic. The incomplete asthma clinics usually lacked sufficient asthma nurse time, a scheduled nurse surgery and a responsible GP. $77 \%$ of the PHCCs had access to a spirometer and on average 19 spirometries/1000 inhabitants/year were performed. There was a large variation in the use of spirometers.

Conclusion: Half of the PHCCs had an asthma clinic and a majority had access to a spirometer. More frequent use of spirometry and increased time provision for the asthma nurse would be likely to produce a substantial improvement in the standard of asthma care in primary health care.

(c) 2005 General Practice Airways Group. Published by Elsevier Ltd. All rights reserved.
\end{abstract}

\section{Introduction}

Asthma is a common disease worldwide with a high burden on society. The prevalence of asthma in Sweden is estimated to be $8 \%$ among adults [1]. Primary health care in Sweden has, during the

\footnotetext{
is Report from the AIM-study group.

* Corresponding author. Tel.: +46 241 498510; fax: +46241498502.

E-mail address: karin.lisspers@ltdalarna.se (K. Lisspers).
}

last decade, taken increasingly more responsibility for common diseases such as asthma and chronic obstructive pulmonary disease (COPD). The first asthma clinic in primary care in Sweden was started in 1987 and since then many asthma clinics have been established in primary health care centres (PHCCs).

There is a debate on whether asthma clinics in primary care are beneficial for patients, costeffective, and whether they are favourable when quality of asthma care is assessed [2]. Several 
studies evaluating asthma clinics have shown that patients attending asthma clinics have fewer symptoms, fewer emergency room visits and less sick-leave than patients in PHCCs with no asthma clinic [3-5]. A cross-sectional study in the same region evaluating management, asthma control and quality of life in Swedish adolescents with asthma has recently been published [6]. However, there is still a need for more prospective, randomised controlled trials $[2,3,7]$.

Spirometry is often necessary for a correct asthma diagnosis and to monitor the course of the disease $[8,9]$. In a Swedish primary health care study, one third of the asthma patients had an incorrect diagnosis [10]. COPD is a disease with both increasing prevalence and mortality. According to international and national guidelines, spirometry is necessary for diagnosing and staging COPD, and in order to differentiate between asthma and COPD [11-13].

In 1998 the Swedish Respiratory Group in Primary Care established criteria for a complete primary care-based asthma clinic [14,15]. These are:

1. Nurse trained in asthma management and treatment

2. General practitioner (GP) responsible for the asthma clinic

3. Access to a spirometer in the ciinlice

4. Investigations accolding to guidelines

5. Patient educatiol according to guide elines

6. Scheduled surgery for the asthina nurse

7. A minimum of 0.5 hours per week per 1000 inhabitants is allocated for the asthma nurse

In the Swedish health care system the county councils are responsible for the health care, meaning that the local organisation and economy may differ somewhat between counties. Primary care is organised into PHCCs where each centre is responsible for a defined population, either by a patient-list or by a defined catchment area. In this study the term catchment area is used for both conditions. The number of GPs at each centre varies depending on the size of the catchment area, but very few centres have only one GP. Each GP is responsible for the patients in his/her catchment area. If there is a need for further consultation the patients are referred to secondary care, mostly a specialist in hospital. If the PHCC has an asthma clinic it is an integrated part of the centre.

As far as we know, no large-scale study has been published evaluating the organisation of primary care asthma management in Sweden or in any other country. The aim of this study was to investigate access to spirometry and the prevalence of nursebased asthma clinics in primary health care in
Sweden, and the extent to which these fulfilled national recommendations.

\section{Study population and methods}

\section{Setting}

The study was conducted in the year 2000 in the Uppsala-Örebro region in Sweden, including seven counties with 1.9 million residents, i.e. $22 \%$ of the Swedish population. The whole population in Sweden was 8.8 million. The region consists of rural areas, small towns and seven medium-sized cities, but none with more than 200,000 residents. The area was at the time of the study served by 240 PHCCs, with catchment areas in the range 1000-20500 residents.

\section{Questionnaires}

A postal questionnaire (Appendix A) was sent to the medically-responsible GPs at the 240 PHCCs. The questions concerned the nurnorer of GPs, the size of the catchmentarea. aceess to a spirometer and organis ation. $\sigma_{f}$ the care of asthma patients. certeres which indicated that they had an asthma clinic wore asketurespond to additional questions conderning the criteria of the Swedish Respiratory Group. The definition of a complete asthma clinic is one that fulfils all seven criteria, and an incomplete asthma clinic is one where one or more criteria are not fulfilled. After two written reminders and telephone calls, 238 out of the 240 primary health care centres returned their questionnaires.

Based on questionnaire data, the PHCCs were arbitrarily classified as small (catchment area with less than 3000 residents), mediumsized (3000-7999 residents), large (8000-11999 residents), or very large (12000 residents or more). The classification was made for practical reasons-small PHCCs would have only one GP. This allowed a comparison of access, use of spirometers and organisation of asthma care, according to size.

An additional survey about the use of spirometry in primary care was conducted in 2002. It was sent to 217 PHCCs in the region with more than 3000 residents in the catchment area. $82 \%$ returned this additional survey.

The study was approved by the Research Ethics Committee at Uppsala University.

\section{Statistical considerations}

Data were analysed with the SPSS (12.0) and SAS statistical programme packages. Summary 
statistics such as medians, means and measures of dispersion were computed using standard parametric methods. Only two-tailed tests were used. $P$-values less than $5 \%$ were considered to indicate a statistical significance and for this reason $95 \%$ confidence intervals were used.

\section{Results}

\section{Characteristics of the study area}

The mean size of the population in the catchment areas was $8101.8 \%$ of the centres were classified as small, $44 \%$ as medium, $31 \%$ as large and $17 \%$ as very large. The mean population size per GP in the whole region was 1886 (range 1175-3500) with a variation between counties $(p<0.001)$. All PHCCs but one in the region managed their own asthma patients.

\section{Distribution and use of spirometers}

77\% (182) of the centres had a spirometer, (Table 1). Each PHCC performed on average 13 spirometries during a month (median 10). $20 \%$ of the PHCF performed 0-2 spirometries, $17 \% 3-5,23 \%$ ही 10 , 24\% 11-20 and 15\% more thal 30 spirometries

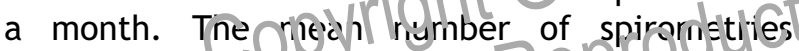
performed per 1000 inhabitants aind year in the whole region was $19(95 \% \mathrm{Cl} 14.91-23.57)$, (Fig. 1).

\section{Criteria for a complete asthma clinic}

One hundred twenty-five centres $(53 \%)$ reported that they had an asthma clinic. The extent to which these fulfilled the criteria for a complete asthma clinic is shown in Table 2. 38 centres (30.4\%) fulfilled all seven criteria, another 38 (30.4\%) fulfilled six criteria, 35 (28\%) fulfilled five

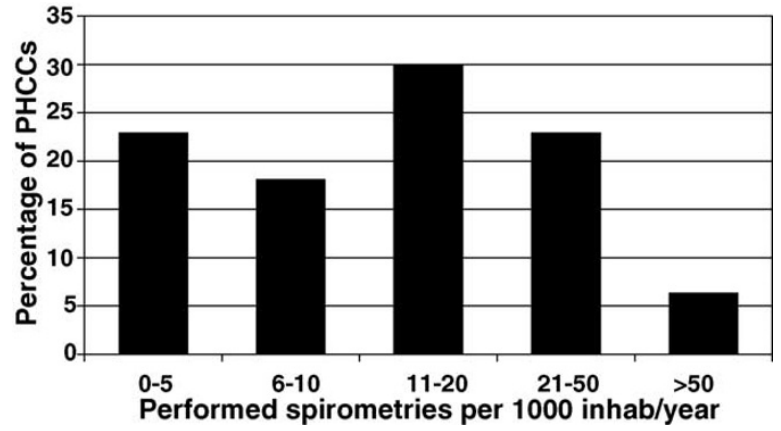

Figure 1 Distribution (\%) of primary health care centres according to number of performed spirometries per 1000 inhabitants yearly.

criteria and the remaining $14(11.2 \%)$ fulfilled one to four criteria. The most common criteria not fulfilled were: time allocation for the asthma nurse; having a scheduled asthma nurse surgery; and having a specially appointed GP responsible for the asthma clinic. Other criteria were to a large extent fulfilled.

\section{Distribution of asthma ciinics UIC}

The dis 0 bution of asthma clinics in the region and in relation to catenront area is shown in Table 1. The tarsen the centre, the greater the probability of having an asthma clinic $(p<0.05)$.

With respect to the whole population in the study area, $17 \%$ of the residents had access to a complete asthma clinic, $42 \%$ to an incomplete clinic, and the remaining $41 \%$ had no asthma clinic access.

\section{Time spent by asthma nurses in the asthma clinics}

In all asthma clinics, the time allocation for the asthma nurse ranged from 0 to 2.1 hours per week per 1000 residents in the catchment area, with a

Table 1 Distribution of primary health care centres $(n=238)$ with spirometers, and asthma clinics which were complete, incomplete, or absent, in relation to catchment area.

\begin{tabular}{|c|c|c|c|c|}
\hline & \multirow{2}{*}{$\begin{array}{l}\text { PHCCs with spirometers } \\
n(\%)\end{array}$} & \multicolumn{3}{|c|}{ Asthma clinic } \\
\hline & & $\begin{array}{l}\text { Complete } \\
n(\%)\end{array}$ & $\begin{array}{l}\text { Incomplete } \\
n(\%)\end{array}$ & $\begin{array}{l}\text { None } \\
n(\%)\end{array}$ \\
\hline Total in the study area & $182(76.5)$ & $38(16.0)$ & $87(36.6)$ & $113(47.5)$ \\
\hline \multicolumn{5}{|l|}{ Catchment area size } \\
\hline small & $8(44.4)$ & 0 & $1(5.6)$ & $17(94.4)$ \\
\hline medium & 79 (76.0) & $18(17.3)$ & $34(32.7)$ & $52(50.0)$ \\
\hline large & $62(82.7)$ & 14 (18.7) & $30(40.0)$ & $31(41.3)$ \\
\hline very large & $33(80.5)$ & $6(14.6)$ & $22(53.7)$ & $13(31.7)$ \\
\hline
\end{tabular}


Table 2 Primary health care centres reporting asthma clinics in the questionnaire and number of fulfilled and missing criteria for a complete asthma clinic according to the Swedish Respiratory Group in Primary Care recommendations.

\begin{tabular}{|c|c|c|c|c|c|c|c|c|c|}
\hline \multirow{2}{*}{$\begin{array}{l}\text { No. of } \\
\text { fulfilled } \\
\text { criteria }\end{array}$} & \multicolumn{2}{|c|}{$\begin{array}{l}\text { Asthma } \\
\text { clinics }\end{array}$} & \multicolumn{7}{|c|}{ Missing criteria for a complete asthma clinic } \\
\hline & $n$ & $\%$ & $\begin{array}{l}\text { Access to } \\
\text { spirometer }\end{array}$ & $\begin{array}{l}\text { Time } \\
\text { criterion }\end{array}$ & $\begin{array}{l}\text { Scheduled } \\
\text { nurse surgery }\end{array}$ & $\begin{array}{l}\text { Patient } \\
\text { education }\end{array}$ & $\begin{array}{l}\text { Patient } \\
\text { investigations }\end{array}$ & $\begin{array}{l}\text { Trained } \\
\text { nurse }\end{array}$ & $\begin{array}{l}\text { Responsible } \\
\text { GP }\end{array}$ \\
\hline 1 & 1 & 0.8 & 0 & 1 & 1 & 1 & 1 & 1 & 1 \\
\hline 2 & 0 & - & 0 & 0 & 0 & 0 & 0 & 0 & 0 \\
\hline 3 & 4 & 3.2 & 2 & 4 & 4 & 2 & 2 & 0 & 2 \\
\hline 4 & 9 & 7.2 & 0 & 9 & 9 & 4 & 0 & 1 & 4 \\
\hline 5 & 35 & 28.0 & 1 & 33 & 24 & 1 & 1 & 0 & 8 \\
\hline 6 & 38 & 30.4 & 0 & 25 & 8 & 0 & 0 & 0 & 5 \\
\hline 7 & 38 & 30.4 & 0 & 0 & 0 & 0 & 0 & 0 & 0 \\
\hline Total & 125 & 100.0 & 3 & 72 & 46 & 8 & 4 & 2 & 20 \\
\hline
\end{tabular}

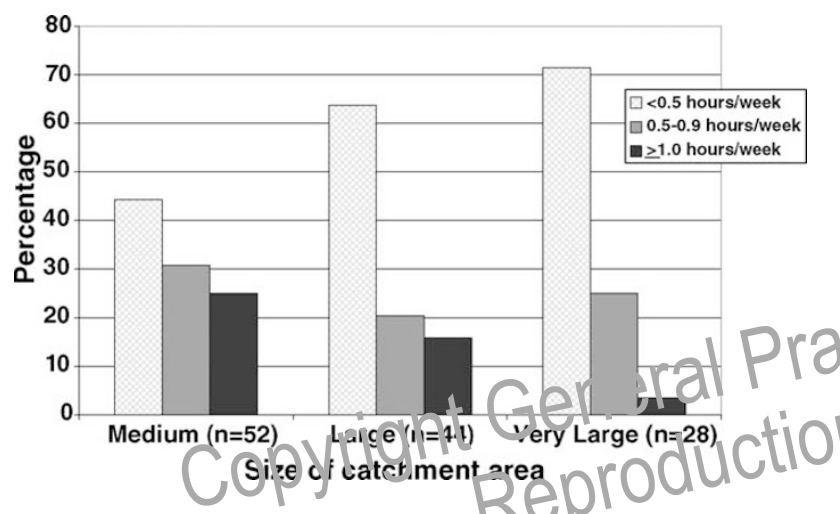

Figure 2 Distribution (\%) of time allocation (hours weekly per 1000 inhabitants) among the PHCCs with asthma clinic according to size of catchment area.

median of 0.42 and a mean of 0.53 hours $(95 \% \mathrm{Cl}$ $0.45-0.62)$.

Among the centres with asthma clinics, the time criterion for the asthma nurse was met in $56 \%$ of the medium-sized centres, in $36 \%$ of the large and in $29 \%$ of the very large centres (Fig. 2). Among the small centres, only one had an asthma clinic and there was no time allocated. In the complete asthma clinics, the time spent by the nurse varied from 0.5 to 2.1 hours per week per 1000 inhabitants, with a mean of $1.0(95 \% \mathrm{Cl}$ 0.90-1.20).

\section{Discussion}

The study area encompasses one fifth of the Swedish population (Fig. 3). With a response rate of $99 \%$, this study provides an almost complete mapping of the organisation of asthma care in the region. The population in this region represents a national average according to gender, age and income. We assume that the results of this study can be applied to the whole nation even though no large cities were included.

In this region, the majority (7) $73 \%$ ? of the centres had a spiromentereas a study in 2000 from the councy of Stockholm, with a population of 4.8 million, reporced that $58 \%$ of the PHCCs had access to a spirumeter [16]. One of the reasons fo this lower figure might be the closer access to pulmonary function laboratories and hospitals in Stockholm.

The number of PHCCs with access to spirometry is high when considered from an international perspective. In a UK study with 209 randomly

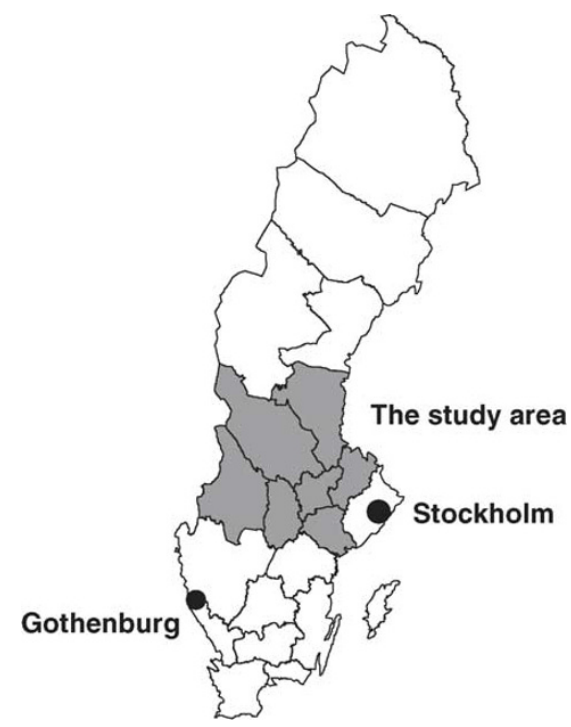

Figure 3 Map of the county councils in Sweden and the study area. 
sampled GPs, 59\% had a spirometer [17]. In a Canadian study of 268 family physicians in Ontario, $40 \%$ reported access to a spirometer (personal communication D'Urzo A, Toronto, Canada).

There was a great difference in the use of spirometry amongst the PHCCs, which can affect the quality of the spirometric data, the possibility of diagnosing and monitoring asthma, and the detection, diagnosis and staging of COPD. Several studies have emphasised the importance of having sufficient training for the staff performing spirometry, in order to obtain good quality spirometric data $[18,19]$.

In the 2004 recommendations for asthma and COPD from the National Board of Health and Welfare in Sweden there is a priority list of what is most important in the care of asthma and COPD in both primary care and secondary care. According to these priorities the optimal level of spirometries in primary care would be at least 60 lung function tests per 1000 inhabitants yearly. Only $6 \%$ of the PHCCs in this study reached more than 50. Important explanations for the discrepancy between the recommended and actual levels might be lack of staff time and insufficient knowledge amongst GPs regarding the importance of spirometry. However, 10 years ago only a minori y of the PHCCs in Sweden had a spirometer. Eday, most PHCCs have spirometers (b) bnty a few centres use nem attording to the recomriended level.

More than half of the centres had an asthma clinic. However, according to the definition of a complete asthma clinic in Swedish national recommendations, only one out of three centres were complete and fulfilled all seven criteria. The main reason for being classified incomplete was that too little time was allocated for the nurse. This study also showed that there was a great variation between asthma clinics in this respect. Several previous studies have evaluated asthma clinic outcomes but we found no studies focusing on the importance of sufficient time allocation for the nurse. The other two most common reasons for being incomplete were the lack of a scheduled nurse surgery and the lack of a GP responsible for the clinic.

We believe it is important that the asthma nurse is well educated in order to provide good quality care and patient education. In Sweden, there are training courses for asthma nurses ranging from commercially available courses lasting a few days to long-term university courses, but there is no recommended minimum standard level. For this reason, we made no evaluation of asthma nurse training. According to international guidelines [8,11], patient education is a priority activity. Swedish studies have shown that an asthma clinic with a well-trained nurse working with GPs is a good way to fulfil this priority within primary health care [5]. In a Norwegian study, the education of asthmatic patients also improved patient outcomes and reduced costs [20].

Many of the centres have invested in spirometers and started asthma clinics without allocating enough time for the activity. The lack of support - especially economic - from the local authorities, local priorities, and traditions, could be important reasons for this. This study shows that relatively small additional resources are needed for many of the incomplete clinics to become complete.

In conclusion, $77 \%$ of the centres had a spirometer and $53 \%$ had an asthma clinic. Most of the incomplete asthma clinics had the structural prerequisites in place, such as a spirometer and a trained asthma nurse, to be considered complete according to national recommendations in Sweden, but the commonest limiting factors were related to time allocation for an aschna larse. Ey eliminating these factcis, a : Lisstantial improvement in the satid (ard of asthma care in primary health care would be pos inte.eC

A fo. Is w up study focusing on management, asthma control, quality of life, and detection of asthma in the population in relation to organisation of asthma care, is in progress.

\section{Conflicts of interest}

None declared.

\section{Acknowledgements}

This study was supported by grants from the county councils of the Uppsala-Örebro Health Care Region, The Centre for Clinical Research, Dalarna, The Swedish Heart and Lung Foundation, The Swedish Asthma and Allergy Association and The Swedish Heart and Lung Association.

We acknowledge all participating centres, the whole AIM-study group including Kristina Bröms MD, Department of Public health and caring Sciences, Uppsala University, and Dan Gustafsson, $M D$, and Florence Andersson, RN, Örebro University Hospital. We would also like to thank Mats Arne, MSc, Primary Care Research Unit, Karlstad, for contributing spirometry data. Special thanks to Jerzy Leppert, MD PhD, Centre for Clinical Research, Västerås for critical review of the manuscript. 


\section{Appendix A. Questionnaire about organisation of asthma care (translated from Swedish)}

1. How many full-time GP-positions are there at your centre? How many GP's are appointed?

2. How many inhabitants are there in your catchment area?

3. Are patients with asthma investigated and treated at your clinic?

$$
\begin{gathered}
\text { Yes } \square \text { No } \square \quad \text { Don't know } \square \\
\text { Yes } \square \quad \text { No } \square \quad \text { Don't know } \\
\text { Yes } \square \quad \text { No } \square \text { Don't know }
\end{gathered}
$$

4. Is your clinic equipped with a spirometer?

5. Does your centre have an asthma clinic?

- If your answer to question 5 is yes, please answer questions 6-11

- If your answer to question 5 is no, the questionnaire is completed.

6. For how many years have your centre had an asthma clinic?

$$
\text { Less than } 1 \text { year } \square \quad 1-3 \text { years } \square \quad \text { More than } 3 \text { years }
$$

7. How many hours are weekly allocated for the asthma clinic?

8. Does the asthma clinic have a specially trained nurse?

$$
\text { Yes } \square \text { No } \square \quad \text { Don't know }
$$

9. Does the clinic have a GP responsible for the asthma clinic?

10. Does the asthma nurse have a scheduled nurgery?

\section{Yes}

11. Does the asthma nurse perform structu re $n$ nd sigations with peak flow measurements, peak flow diary and calculations of variability and reversibility at the asthma clinic?

$$
\text { Yes } \square \quad \text { No } \square \quad \text { Don't know }
$$

12. Does the asthma nurse educate the patient about asthma, medication, treatment plans and prevention?

$$
\text { Yes, often } \square \quad \text { Yes, now and then } \square \quad \text { No } \square \text { Don't know }
$$

\section{References}

[1] Lundbäck B. Epidemiology of asthma and rhinitis. Clin Exp Allergy 1998;28:3-10.

[2] Premaratne UN, Sterne JA, Marks GB, Webb JR, Azima H, Burney PG. Clustered randomised trial of an intervention to improve the management of asthma. Greenwich asthma study. BMJ 1999;318:1251-5.

[3] Treating Asthma and COPD. A systematic review [Authors' translation]. The Swedish Council on Technology Assessment in Health Care. Report 151, Stockholm 2000.

[4] Heard AR, Richards IJ, Alpers JH, Piltto LS, Smith BJ, Black JA. Randomised controlled trial of general practice based asthma clinics. Med J Aust 1999;171:68-71.

[5] Lindberg M, Ahlner J, Möller M, Ekström T. Asthma nurse practice - a resourse-effective approach in asthma management. Respir Med 1999;93:584-8.

[6] Hasselgren M, Gustafsson D, Ställberg B, Lisspers K, Johansson G. Management, asthma control and quality of life in Swedish adolescents with asthma. Acta Pediatrica 2005; 94. In press.

[7] Fay JK, Jones A, Ram FSF. Primary care based clinics for asthma (Cochrane Review). In: The Cochrane Library, Issue 4, 2002. Oxford: Update Software.

[8] Global Initiative For Asthma (GINA). Global Strategy for Asthma Management and Prevention. NHLBI/WHO Workshop Report, 2002.

[9] British Guideline on the Management of Asthma. Thorax 2003; 58 (Suppl I).

[10] Marklund B, Tunsäter A, Bengtsson C. How often is the diagnosis bronchial asthma correct? Family Practice 1999;16:112-6.

[11] GOLD. Global strategy for the diagnosis, management and prevention of chronic obstructive pulmonary disease. NHLBI/WHO workshop report 2001. Publication number 2701A.

[12] Ferguson GT, Enright PL, Buist AS, Higgins MW. Office Spirometry for Lung Health Assessment in Adults. A Consensus Statement From the National Lung Health Education Program. Chest 2000;117:1146-61. 
[13] Behandling av kroniskt obstruktiv lungsjukdom - KOL [Treatment of COPD, authors' translation]. Information från Läkemedelsverket. Uppsala, Sweden: Medical Products Agency, 2002; 4.

[14] Tilling B, Johansson G, Ställberg B. Astmamottagning i primärvården - dags att fastslå kriterier! [Asthma clinic in primary health care - time to establish criteria! Authors' translation]. AllmänMedicin 1998;19: 141-2.

[15] Farmakologisk behandling vid astma. [Pharmacological asthma treatment, authors' translation]. Information från Läkemedelsverket. Uppsala, Sweden: Medical Products Agency, 2002; 2.

[16] Handlingsprogram för allergi och annan överkänslighet [Action programme for allergy and hypersensitivity, authors' translation]. Stockholm, Sweden: Stockholm County Council HSN, 2002:18.

[17] Rudolf M, abstract BTS winter meeting 1999. Thorax 1999; 54 suppl 3.

[18] Schermer TR, Jacobs JE, Chavannes NH, et al. Validity of spirometric testing in general practice population of patients with chronic obstructive pulmonary disease (COPD). Thorax 2003;58(10):861-6.

[19] Eaton T, Withy S, Garrett JE, Mercer J, Whitlock RM, Rea $\mathrm{HH}$. Spirometry in primary care practice: the importance of quality assurance and the impact of spirometry workshops. Chest 1999;116(2):416-23.

[20] Gallefoss F, Bakke PS. The effect of patient education in asthma, a randomized controlled trial. Tidsskr Nor Laegeforen 2002;122(28):2702-6.

\section{Available online at http://www.thepcrj.com}

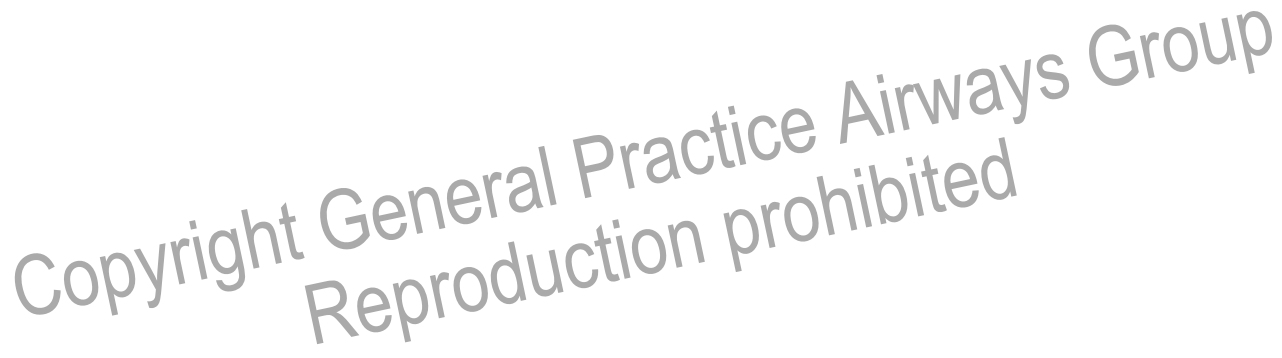

